\title{
FAKTOR-FAKTOR YANG MEMPENGARUHI LONELINESS PADA PARA LANJUT USIA DI WISMA CINTA KASIH PADANG
}

\author{
Rismar Julia Utami \\ STKIP Muhammadiyah Sungai Penuh \\ J1. Muradi Sungai Liuk Kota Sungai Penuh Kerinci - Jambi \\ Email: rj_utami@yahoo.co.id
}

\begin{abstract}
ABSTRAK
Penelitian ini merupakan penelitian yang bertujuan untuk melihat faktor yang mempengaruhi loneliness pada para lanjut usia. kesepian adalah suatu perasaan yang tidak menyenangkan disebabkan adanya ketidaksesuaian antara hubungan sosial yang diharapkan dengan kenyataan kehidupan interpersonalnya akibat terhambat atau berkurangnya hubungan sosial yang dimiliki seseorang. Jumlah sampel penelitian ini adalah 24 orang lansia yang terdiri dari 5 orang lansia laki-laki $(20 \%)$ dan 19 orang lansia wanita $(80 \%)$. Pengambilan sampel dilakukan dengan menggunakan purposive sampling. Pendekatan penelitian yang digunakan dalam penelitian ini adalah pendekatan fenomenologis dengan menggunakan wawancara tidak terstruktur sebagai teknik pengumpulan data. Data yang diperoleh kemudian dibuatkan ke dalam verbatim (transkrip) yang kemudian dianalisis dengan melakukan pengkodean pada setiap hasil wawancara dan menggunakan teknik analisi isi (content analysis) untuk menyimpulkan hasil penelitian, dalam penelitian ini diperoleh hasil yang menunjukkan bahwa faktor dominan yang mempengaruhi terjadinya loneliness pada para lanjut usia adalah sifat introvert, yang diperoleh dari subjek penelitian sebanyak 17 orang (33\%).
\end{abstract}

\section{Kata Kunci : Loneliness, Lanjut Usia}

\section{PENDAHULUAN}

Manusia dalam hidupnya akan mengalami perkembangan dalam serangkaian periode yang berurutan, mulai dari periode prenatal sampai lanjut usia. Semua individu mengikuti pola perkembangan dengan pasti dan dapat diramalkan. Setiap masa yang dilalui merupakan tahap-tahap yang saling berkaitan dan tidak dapat diulang kembali. Hal-hal yang terjadi di masa awal perkembangan individu akan memberikan pengaruh terhadap tahap-tahap selanjutnya. Salah satu tahap yang akan dilalui oleh individu tersebut adalah masa lanjut usia atau lansia (Hurlock, 2004).

Usia lanjut merupakan masa yang memiliki masalah tersendiri dalam kehidupan sosial. Sejak dulu telah diketahui bahwa faktor emosional erat kaitannya dengan kesehatan mental lanjut usia. Aspek emosional yang terganggu, kecemasan apalagi stres berat, dapat secara tidak langsung mencetuskan gangguan terhadap kesehatan fisik, seperti sebaliknya gangguan kesehatan fisik (tubuh) dapat berakibat terhadap stabilitas emosional (Hurlock, 2004).

Kusumiati (2008) mengungkapkan terdapat tiga masalah pokok psikologis yang dialami para lanjut usia, pertama adalah masalah yang disebabkan oleh perubahan hidup dan kemunduran fisik yang dialami oleh lanjut usia. Kedua, lanjut usia sering mengalami kesepian yang disebabkan oleh putusnya hubungan dengan orang-orang yang paling dekat dan disayangi. Ketiga, post power syndrome, hal tersebut banyak dialami oleh lanjut usia 
yang baru saja mengalami pensiun, kehilangan kekuatan, penghasilan dan kebanggaan. Memasuki usia lanjut, menyebabkan para lanjut usia mengalami beberapa kemunduran yang mengakibatkan lanjut usia membutuhkan dukungan dari orang lain termasuk pasangan hidupnya, oleh karena itu kehilangan pasangan hidup dapat menurunkan kesejahteraan psikologis pada pasangan yang ditinggalkan, hal ini terjadi karena berkurangnya minat pada pasangan yang ditinggalkan untuk menjalin hubungan yang positif dengan orang lain.

Berkurangnya minat ini ditunjukkan dengan penarikan dan penutupan diri yang dapat mengakibatkan perasaan kesepian atau loneliness pada lanjut usia. Kondisi lanjut usia yang mengalami berbagai penurunan atau kemunduran baik fungsi biologis maupun psikis dapat mempengaruhi mobilitas dan juga kontak sosial, salah satunya adalah isolation atau rasa kesepian (loneliness), terkucil atau merasa tidak diperhatikan lagi, bahkan yang lebih serius adalah depresi. Loneliness dilihat sebagai suatu fakta kehidupan, salah satu resiko alamiah, suatu resiko pekerjaan dari mereka yang bernafas. Salah satu mitos ide menyatakan bahwa orang lanjut usia adalah yang paling loneliness, (http://etd.eprints.ums.ac.id).

Berdasarkan hasil wawancara yang dilakukan dengan seorang ibu yang berinisial $\mathrm{K}$ (65 Tahun), menceritakan bahwa kedua anaknya menjual rumah peninggalan ayah mereka setelah satu tahun suaminya meninggal, kedua anak ibu K sepakat menjual rumah itu dan membagi uangnya sebagai warisan, kedua putranya tidak mau bertanggung jawab merawat dirinya, akhirnya mereka juga yang memutuskan memasukkan ibu K ke panti jompo dengan begitu saja tanpa ada kelanjutannya. Ada juga seorang bapak dengan inisial T (67 Tahun) mengisahkan pada peneliti karena anaknya merasa sibuk dengan pekerjaannya yang mana mereka sering pulang di malam hari, dan tidak ada orang yang akan merawat serta menjaga bapaknya, akhirnya mereka memutuskan untuk memasukkan bapak mereka ke Wisma Cinta Kasih, begitu pula yang diceritakan oleh ibu W (78 tahun) merasa kehilangan setelah suaminya meninggal sepuluh tahun silam serta kematian tiga anaknya membuat membuat ibu W memilih tinggal di panti. Terlebih tiga anaknya sudah menikah. Ibu W mempunyai enam anak yang ke semuanya perempuan. Ibu W tidak ingin memberatkan keluarga serta anaknya yang sudah menikah.

Seiring dengan bertambahnya usia, maka akan bertambah pula permasalahan pada lanjut usia. Para lanjut usia pada dasarnya membutuhkan perhatian tersendiri karena lanjut usia membutuhkan kehangatan, dihargai, hubungan sosial, dan juga seks yang sebagian menjadi kebutuhan fisik atau psikis. Sebenarnya orang lanjut usia tidak akan menimbulkan masalah yang berarti bagi individu lanjut usia terutama keluarganya, apabila keluarga masih sanggup merawatnya, tetapi bila keluarganya menjadi semakin sibuk sehingga tidak memiliki cukup waktu dan tenaga untuk merawat dan memperhatikannya, salah satu jalan yang dipilih adalah menempatkan orang lanjut usia di panti.

Berdasarkan paparan di atas ada beberapa lanjut usia merasa kurang senang tinggal di wisma karena dirinya merasa kurang diperhatikan, kurang dapat kasih sayang dan kurang adanya penerimaan dari keluarga. Ada pula yang merasa kesepian atau loneliness, mereka mengungkapkan bahwa mereka yang tinggal di wisma cinta kasih mengalami keterasingan, loneliness, isolasi sosial serta tidak tahu harus berbuat apa untuk mengisi masa tuanya itu.

Loneliness merupakan hasil interaksi dengan individu lain yang tidak sesuai dengan apa yang diharapkan sebelumnya. Sears, dkk (dalam Santrock, 2002) mendefinisikan loneliness 
sebagai suatu pengalaman subjektif yang tidak mengenakan baik dari segi kuantitas maupun kualitas. Segi kuantitas, seorang lanjut usia merasa tidak punya teman dan atau mempunyai teman namun kurang dari yang diharapkan, dari segi kualitas, lanjut usia merasa bahwa hubungannya dengan orang lain sangat dangkal, kurang memuaskan dan tidak sesuai dengan yang diharapkan, walaupun ada banyak orang di sekitarnya.

Loneliness yang dialami oleh lanjut usia yang tinggal di panti didefinisikan sebagai keadaan subjektif yang menekan yang dialami oleh lanjut usia sebagai reaksi ketidakpuasan atas hubungan yang lanjut usia harapkan dengan keadaan nyata yang sebenarnya (Hurlock, 2004). Munculnya rasa tersisih, tidak dibutuhkan lagi, ketidakikhlasan menerima kenyataan baru seperti penyakit yang tidak kunjung sembuh, kematian pasangan, merupakan sebagian kecil dari keseluruhan perasaan yang tidak enak yang harus dihadapi lanjut usia. Seseorang yang lanjut usia tidak akan mengalami loneliness apabila dapat menyesuaikan diri dengan keadaan lingkungan barunya dan menjalin hubungan dengan orang lain yang seusianya.

Keadaan didalam panti dapat menjadi stressor baik yang berasal dari dirinya sendiri maupun dari lingkungannya dan beban terberat yang dipikul orang berusia lanjut adalah kesepian atau loneliness, benih yang darinya akan tumbuh sejumlah masalah lain, walaupun kadang-kadang penempatan orang usia lanjut di suatu panti maupun lembaga-lembaga sosial disebabkan oleh karena keinginan para lanjut usia itu sendiri atau karena kondisi keluarga, bagaimanapun juga penempatan di panti tersebut merupakan penyelesaian yang tidak disukai, (http://etd.eprints.ums.ac.id).

\section{METODE PENELITIAN}

Pendekatan yang digunakan pada penelitian ini adalah pendekatan fenomenologi. Pendekatan fenomenologi merupakan pendekatan yang bertitik tolak pada pandangan berpikir yang menekankan pada pengalaman-pengalaman yang bersifat subjektif manusia (Moleong, 2002). Metode yang digunakan dalam penelitian ini adalah metode kualitatif di mana data deskriptif yang diperoleh berupa kata-kata tertulis atau lisan dari orang-orang dan perilaku yang dapat diamati Bogdan dan Taylor (dalam Moleong, 2002). Data yang dikumpulkan dalam penelitian kualitatif semata-mata hanya bersifat deskriptif sehingga tidak bermaksud menguji hipotesis, membuat prediksi, maupun mempelajari implikasi.

Jumlah sampel penelitian ini adalah 24 orang lansia yang terdiri dari 5 orang lansia lakilaki $(20 \%)$ dan 19 orang lansia wanita (80\%). Pengambilan sampel dilakukan dengan menggunakan purposive sampling. Teknik pengumpulan data yang digunakan adalah wawancara yang dilakukan dalam penelitian ini bersifat terbuka dan tidak terstruktur. Peneliti tidak dapat meramalkan kemana arah wawancara berkembang. Pertanyaan dalam wawancara berkembang menurut perkembangan wawancara itu secara wajar berdasarkan ucapan dan buah pikiran yang dicetuskan oleh subjek. Data yang diperoleh kemudian dibuatkan ke dalam verbatim (transkrip) yang kemudian dianalisis dengan melakukan pengkodean pada setiap hasil wawancara dan menggunakan teknik analisi isi (content analysis). Pada penelitian ini peneliti menggunakan pendekatan analisis isi (content analysis). Holsti (dalam moleong, 2002) menyatakan bahwa analisis isi (content analysis) adalah teknik apa pun yang 
digunakan untuk menarik kesimpulan malalui usaha, menemukan karakteristik pesan yang dilakukan secara objektif dan sitematis.

\section{HASIL DAN PEMBAHASAN}

Penelitian ini dilakukan terhadap 24 orang para lanjut usia yang tinggal di Wisma Cinta Kasih Padang, dimana diperoleh hasil deskripsi jenis kelamin subjek penelitian yang menunjukkan laki-laki berjumlah 5 orang (20\%) dan perempuan 19 orang $(80 \%)$. Lesmana (dalan Juniarti, 2008) menyatakan bahwa kesepian merupakan salah satu tema dari 14 sub tema utama yang ada pada lansia yaitu kesepian, isolasi sosial, kehilangan, kemiskinan, perasaan ditolak, perjuangan menemukan makna hidup, kebermaknaan hidup, perasaan tidak berguna, tidak berdaya, putus asa dan lain sebagainya.

\section{A. Gambaran Loneliness pada Para Lanjut Usia}

Berdasarkan hasil wawancara yang telah dilakukan diperoleh bahwa para lansia yang tinggal di Wisma Cinta Kasih Padang mengalami kesepian, terutama pada para lanjut usia wanita lebih mengalami kesepian dibandingkan para lanjut usia laki-laki, dimana diperoleh hasil deskripsi tingkat perbandingan loneliness pada lanjut usia berdasarkan jenis kelamin, subjek penelitian yang menunjukkan laki-laki berjumlah 1 orang $(20 \%)$ dan perempuan 4 orang $(80 \%)$.

Peters (dalam Juniarti, 2008) menyatakan bahwa tingkat kesepian dapat dilihat berdasarkan jenis kelamin lansia, dari hasil penelitian menyatakan bahwa baik lansia laki-laki maupun perempuan mempunyai kecenderungan yang sama yaitu mengalami kesepian yang sama, namun beberapa peneliti menyatakan bahwa lansia wanita lebih cenderung merasa kesepian di bandingkan pria, penelitian ini menemukan bahwa faktor gender menjadi prediksi yang signifikan penyebab terjadinya kesepian.

\section{B. Faktor-faktor yang Mempengaruhi Loneliness pada Para Lanjut Usia}

Faktor personal dan kultural adalah karakteristik kepribadian seseorang yang memainkan peran yang cukup signifikan dalam mengembangkan perasaan loneliness. Perlau dan Perlman (dalam Santrock, 2002), menyebutkan bahwa karakteristik kepribadian seperti self esteem yang rendah, social anxiety, pemalu dan kurang asertif dapat menimbulkan kesulitan bagi individu dalam membangun atau mencapai kepuasan dalam hubungan sosial dengan orang lain, dengan demikian juga meningkatkan kemungkinan terciptanya loneliness. Selain itu, Jones dan Rotenberg (2008), menyebutkan bahwa kepribadian yang sinis, introvert dan kepercayaan yang kurang juga terdapat pada diri yang loneliness, (dalam Sutoyo, 2010).

Yeagley (2008) mengatakan bahwa loneliness pada lanjut usia dapat disebabkan oleh berbagai faktor sosial, yakni kemandirian dan ketergantungan diri. Dua hal tersebut sering didengungkan sebagai sebuah usaha untuk mencapai kemajuan dan sukses. Kerja tim tampaknya sudah tergantikan oleh inisiatif individu, sehingga individu merasa tidak lagi perlu untuk berhubungan dan tergantung pada orang lain, hal ini menyebabkan loneliness. Penyakit, juga menyebabkan orang diasingkan dan menghindari sosialisasi, (dalam Sutoyo, 2010). 
Berdasarkan hasil wawancara diketahui bahwa terdapat sembilan (9) faktor yang mempengaruhi terjadinya loneliness pada para lanjut usia, faktor paling dominan yang mempengaruhi terjadinya loneliness pada para lanjut usia adalah bersifat introvert atau kurang terbuka yang terjadi pada 17 orang (33\%).

Tabel 1. Deskripsi Tally Faktor-Faktor Yang Mempengaruhi Loneliness Pada Lanjut Usia

\begin{tabular}{|c|c|c|c|c|}
\hline No & Faktor & Tally & Jumlah & $\%$ \\
\hline \multirow[t]{8}{*}{1} & Personal dan kultural & & & \\
\hline & a. Bersifat introvet atau kurang terbuka & IXV IIII IIII II & 17 & $33 \%$ \\
\hline & $\begin{array}{l}\text { b. Kepribadian yang sinis atau mudah } \\
\text { curiga }\end{array}$ & IX & 4 & $8 \%$ \\
\hline & c. Merasa kurang percaya diri & $\searrow$ & 6 & $12 \%$ \\
\hline & d. Self esteem yang rendah atau merasa & IX I & & \\
\hline & kurang dihargai & $\mathbf{X X}$ & 5 & $10 \%$ \\
\hline & $\begin{array}{l}\text { e. Merasa kurang nyaman atau social } \\
\text { anxiety }\end{array}$ & II & 2 & $4 \%$ \\
\hline & f. Kurang asertif & I & 1 & $2 \%$ \\
\hline \multirow[t]{3}{*}{2} & Sosial & & & \\
\hline & a. Kemandirian & IIII & 4 & $8 \%$ \\
\hline & b. Ketergantungan diri & IXI II & 7 & $13 \%$ \\
\hline \multirow[t]{3}{*}{3} & Lain-lain & & & \\
\hline & Jarang dikunjungi & Int & 5 & $10 \%$ \\
\hline & JUMLAH & & 51 & $100 \%$ \\
\hline
\end{tabular}

Berdasarkan tabel 1 di atas, diperoleh hasil deskripsi dari faktor-faktor yang mempengaruhi loneliness pada lanjut usia menunjukkan bahwa berdasarkan faktor personal yang dilihat berdasarkan sifat introvert atau kurang terbuka sebanyak 17 orang (33\%), kepribadian sinis atau mudah curiga sebanyak 4 orang $(8 \%)$, merasa kurang percaya diri sebanyak 6 orang $(12 \%)$, self esteem yang rendah atau merasa kurang dihargai sebanyak 5 orang (10\%), merasa kurang nyaman atau social anxiety sebanyak 2 orang (4\%), kurang asertif sebanyak 1 orang (2\%). Faktor sosial yang dilihat berdasarkan kemandirian sebanyak 4 orang $(8 \%)$, ketergantungan diri sebanyak 7 orang (13\%). Faktor lain-lain yang dilihat berdasarkan jarang dikunjungi keluarga sebanyak 5 orang (10\%).

Hal ini sesuai dengan penelitian yang dilakukan oleh pratiwi (2001) tentang kesepian yang ditinjau dari aktivitas dan tempat tinggal orang lansia pensiun yang bertipe kepribadian introvert dan ekstrovert, diperoleh hasil yakni lansia yang berkepribadian introvert lebih tinggi mengalami kesepian dari pada para lansia yang berkepribadian ekstrovert, selain itu peneliti juga menemukan faktor lain yang mempengaruhi loneliness pada para lanjut usia yakni jarang dikunjungi oleh keluarga sebanyak 5 orang (10\%). 


\section{KESIMPULAN DAN SARAN}

\section{Kesimpulan}

Berdasarkan hasil penelitian dan pembahasan yang telah diuraikan sebelumnya, maka dapat disimpulkan bahwa :

1. Hasil penelitian menyatakan bahwa baik lansia laki-laki maupun perempuan mempunyai kecenderungan yang sama yaitu mengalami kesepian yang sama, namun ditemukan hasil bahwa lansia wanita lebih cenderung merasa kesepian di bandingkan pria dengan perbadingan lansia wanita sebanyak 4 orang $(80 \%)$ dan lansia pria sebanyak 1 orang $(20 \%)$.

2. Berdasarkan hasil penelitian diketahui bahwa terdapat sembilan (9) faktor yang mempengaruhi terjadinya loneliness pada para lanjut usia, faktor paling dominan yang mempengaruhi terjadinya loneliness pada para lanjut usia adalah bersifat introvert atau kurang terbuka yang terjadi pada 17 orang (33\%).

3. Peneliti menemukan faktor lain yang juga mempengaruhi terjadinya loneliness pada para lanjut usia yakni jarangnya dikunjungi oleh keluarga sebanyak 5 orang (10\%).

\section{Saran}

Berdasarkan kesimpulan yang telah peneliti kemukakan di atas, maka peneliti menyarankan beberapa hal, sebagai berikut :

1. Subjek penelitian: penelitian disarankan agar tetap beraktivitas dan melakukan kontak atau hubungan sosial yang lebih baik lagi di lingkungan Wisma Cinta Kasih sehingga tidak lagi mengalami perasaan loneliness dan dapat menjalani kehidupan masa tua yang lebih bahagia.

2. Keluarga subjek: disarankan agar lebih memperhatikan para lansia terlebih para lansia tersebut tinggal jauh dari keluarga mereka karena dengan hal tersebut dapat menjadi suatu bentuk dukungan mental bagi lansia tersebut.

3. Masyarakat: Masyarakat diharapkan dapat memberikan perlakuan yang tepat kepada lansia, terutama yang berkaitan dengan kehidupan interpersonalnya seperti bersosialisasi, berkomunikasi, dan berinteraksi, sehingga para lansia tidak merasakan perasaan kesepian.

4. Bagi pimpinan Wisma Cinta Kasih di Padang: diharapkan dapat lebih memperhatikan perilaku para lanjut usia sehingga dapat diketahui faktor apa saja yang mungkin mempengaruhi terjadinya loneliness pada para lanjut usia.

\section{DAFTAR PUSTAKA}

Hurlock, Elizabeth B. 2004. Psikologi Perkembangan Suatu Pendekatan Sepanjang Rentang Kehidupan. Edisi ke-5. Jakarta : Erlangga.

Juniarti.2008. Gambaran Jenis dan Tingkat Kesepian pada Lansia di Balai Panti sosial Werdha Bandung. On line. http://etd.eprints.unpad.ac.id.

Kusumiati Endang.R.Y. 2000. Tinggal Sendiri Di Masa Lanjut Usia. Humanitas, 2008. Volume 6, No.1, halaman 24-43. Universitas Surabaya 
Moleong, L. J. 2002. Metode Penelitian Kualitatif. Bandung: PT. Remaja Rosdakarya.

Pratiwi. 2001. Kesepian yang Ditinjau dari Aktivitas dan Tempat Tinggal Orang Lansia Pensiun yang Bertipe Kepribadian Introvert dan Ekstrovert On line. http://etd.eprints.unpad.ac.id.

Santrock, J.W. 2002. Life-Span Development: Perkembangan Masa Hidup Jilid 2. Edisi Kelima. Penerjemah: Juda Damanik dan Achmad Chusairi. Jakarta: Erlangga.

Sutoyo. 2009. Lonelinness pada Lanjut Usia di Panti Wredha. On line. http://etd.eprints.ums.ac.id. 